\title{
O neoliberalismo e as relações raciais: o não-lugar do racismo estrutural nos editoriais sobre a morte de George Floyd
}

\author{
João Fernando de Lima Parra \\ Recebido em março de 2021 \\ Aceito em junho de 2021
}

\begin{abstract}
RESUMO
O racismo figura como um elemento estrutural nas sociedades capitalistas, no entanto, o tema ainda é debatido como conjunto de ações individuais ou práticas institucionais. A morte de George Floyd reacendeu o debate racial de uma forma inédita, colocando o tema em evidência em grande parte da mídia mundial. Com a notoriedade, se abriu uma janela de oportunidade para colocar em pauta o racismo estrutural. Com o objetivo de verificar como o tema foi tratado pela mídia e se houve menções a este caráter totalizante, foram analisados trinta e quatro artigos de opinião do jornal Folha de São Paulo, cobrindo o período posterior ao assassinato, até o dia do funeral em Houston, Texas. Foi possível evidenciar que são poucos artigos que tratam do caráter estrutural do racismo, sendo que o termo é obliterado pela maioria dos autores. O neoliberalismo e sua ideologia baseada na igualdade de condições entre os indivíduos é um forte limitador do entendimento do caráter estrutural do racismo que contribui com a manutenção de privilégios de uma classe em detrimento de outra. Os resultados mostram que há uma dificuldade em abordar o termo, pois admitir a sua existência implica em aceitar o aspecto segregacionista de uma sociedade que beneficia os brancos, não simplesmente excluindo um grande contingente de negros e negras, mas se beneficiando desta exclusão.
\end{abstract}

Palavras-chave: Racismo estrutural; Mídia; Neoliberalismo; George Floyd.

\section{Neoliberalism and race relations: the non-place of structural racism in the editorials about the death of George Floyd.}

\begin{abstract}
Racism figures as a structural element in capitalist societies, however, the theme is still debated as a set of individual actions or institutional practices. The death of George Floyd rekindled the racial debate in an unprecedented way, putting the issue in evidence in much of the world's media. With the notoriety, a window of opportunity was opened to put structural racism on the agenda. In order to verify how the theme was handled by the media and whether there were mentions of this totalizing character, thirtyfour opinion articles from the newspaper Folha de São Paulo were analyzed, covering the period after the murder, until the day of the funeral in Houston, Texas. It was possible to evidence that there are few articles that deal with the structural character of racism, and the term is obliterated by most authors. Neoliberalism and its ideology based on equality of conditions between individuals is a strong limiting
\end{abstract}

${ }^{1}$ Bacharel em Marketing e Propaganda pela Universidade Norte do Paraná (2007), Bacharel em Sociologia pela Fundação Escola de Sociologia e Política de São Paulo (2016), Mestre em Marketing e Investigación de Mercados pela Universitat de València (2009), Mestre em Ciências Sociais pela Universidade Estadual de Londrina (2019) e Doutorando em Sociologia pela Universidade Estadual de Londrina. Bolsista CAPES/DS. Email: joaoparra@hotmail.com. 
factor in the understanding of the structural character of racism that contributes to the maintenance of privileges of one class over another. The results show that there is a difficulty in approaching the term, as admitting its existence implies accepting the segregationist aspect of a society that benefits whites, not simply excluding a large contingent of black men and women but benefiting from this exclusion.

Keywords: Structural racism, Media, Neoliberalism, George Floyd.

mundo se levantou com a morte brutal de George Floyd no dia 25 de maio de 2020 sob o joelho de um policial branco. A cena foi registrada em vídeo, no qual vemos o policial Derek Chauvin com as mãos no bolso, como se estivesse tranquilamente passeando, em vez de estar obstruindo as vias respiratórias de um ser humano.

Este artigo foi escrito no dia seguinte a eleição que consagrou a derrota do Presidente Donald Trump. Ainda não há como afirmar, com bases empíricas, se a derrota foi um resultado direto das manifestações que ocorreram logo após a morte de George Floyd. Os protestos (este e outros que aconteceram no espaço entre a morte de George Floyd e a eleição), foram usados pelos dois candidatos como trunfo eleitoral, Biden pelas reações desrespeitosas do atual mandatário, e Trump destacando os atos de vandalismo e violência praticados durante as manifestações.

$\mathrm{O}$ que se pode afirmar, com base nos resultados eleitorais, é que Biden conseguiu vitórias importantes em cidades como Detroit e Filadélfia, com a ajuda dos votos de negros e negras - sem contar o caso do Estado da Georgia, que deu ao futuro presidente uma votação histórica que não acontecia desde 1992. Esse fenômeno teve um relevante efeito simbólico, uma vez que se trata de um Estado "historicamente marcado pela supressão do voto negro" (MATTOS, 2020).

Mesmo com a vitória de Biden e o ineditismo de uma mulher de ascendência negra e asiática na vice-presidência, ainda é cedo para afirmar que os atos estremeceram, de alguma forma, as bases estruturais sobre o modo como o racismo é visto na sociedade americana. Não sabemos se as manifestações pela morte de George Floyd terão comoção diferente quando avaliamos seu impacto institucional em relação as práticas de discriminação racial quando comparadas às de 1992, em Los Angeles e a de 2014, no estado do Missouri, que deram origem ao slogan "black lives matter". O que fica latente é que no bojo de toda essa revolta, justa e necessária, se coloca a 
questão de por que o assassinato de um negro americano colocou o racismo na pauta jornalística (brasileira) de uma maneira quase que inédita² (LIMA, 2020).

A questão racial, junto com previsíveis comparações entre a reação da sociedade americana e brasileira, veio à tona nos meios televisivos, acadêmicos e em rodas de conversa pelo Brasil afora. Não quero me deter sobre as diferenças entre os tipos de racismo nos dois países, acredito que muito já foi escrito sobre o tema e uma longa reflexão só reforçaria alguns aspectos sobre as semelhanças³. Tenho o objetivo de destacar aqui como a questão do racismo é debatida na mídia no contexto neoliberal brasileiro. Tomo como hipótese inicial que é tratado como um fato execrável e digno de pena e condenação legal, mas ainda enquanto uma atitude individual, anulando assim o seu caráter sistêmico - ou melhor estrutural. E um dos pontos que corroboram essa individualização está relacionado com os valores neoliberais, que soube imprimir em forma de ideologia a ideia de que não importa a classe e sim o mérito de cada um, através de suas livres escolhas individuais, obliterando a sua função estrutural e estruturante da sociedade (ALMEIDA, 2018).

Dessa forma, o sucesso é visto como corolário da vida de cada indivíduo, e o seu fracasso é responsabilidade única e exclusiva dessas ações. Penso que a sociedade neoliberal contribui para a perpetuação das forças estruturais de racismo de uma maneira singularmente efetiva, pela negação de sua existência, em seu melhor papel de mito de uma sociedade pós-racial (ROBERT, 2016).

Neste sentido, faremos uma análise de artigos de opinião do maior jornal em circulação no país, a Folha de São Paulo. Como recorte temporal, o foco será do dia

\footnotetext{
${ }^{2}$ Para clarificar o "ineditismo" que a autora está se referindo, vale mencionar que o assassinato de negros por agentes do Estado é uma constante no Brasil. Para se ter uma ideia 75,7\% de todos os homicídios no ano de 2018 são de negros e pardos (ATLAS DA VIOLÊNCIA, 2020). Mesmo diante destes indicadores não há o mesmo nível de notoriedade e, muito menos, espaço nos meios de comunicação do país como foi do caso George Floyd.

3 Para mais informações sugiro a leitura do artigo "Preconceito racial de marca e preconceito racial de origem" de Oracy Nogueira (2006), nele o autor destaca a existência de singularidades do racismo nesses dois países e que, apesar das semelhanças, no que se refere aos impactos do racismo em relação a população negra, a discriminação racial no Brasil se baseia no preconceito de marca (fenótipo ou aparência) e não de origem (características biológicas ou ascendência) que independe da aparência, como nos Estados Unidos.
} 
seguinte à morte de George Floyd, até o final de semana ${ }^{4}$ após o seu funeral, no dia 04 de junho. Dessa forma, poderemos avaliar a repercussão, não só do episódio que gerou a sua morte, mas também todo o efeito dos protestos passando pelas reações políticas dos governantes e pelo espraiamento da revolta por outros países. Foram avaliados 26 artigos de nomes de autores dos mais variados tipos e espectros ideológicos.

Para um maior entendimento sobre a questão do racismo estrutural e de como ele está relacionado ao neoliberalismo, é de fundamental importância dedicar algumas linhas a respeito da questão racial (2) e como ela foi (e ainda é) tratada, aqui no Brasil (3), para depois concentrarmos forças no discurso neoliberal da sociedade pós-classe (4). Logo após a fundamentação teórica, analisaremos os artigos de opinião (5), para, na sequência, concluir com as considerações finais.

\section{Raça, racismo, discriminação racial}

Não há uma maneira fácil e sintética de esclarecer temas tão amplos e densos a respeito da raça, racismo e a discriminação racial. O que pretendo aqui é fazer um pequeno panorama destes tópicos, baseado nas obras de Silvio Almeida $O$ racismo estrutural (2018) e Aníbal Quijano Colonialidade do poder, eurocentrismo e América Latina (2005) para que seja possível um embasamento teórico para as análises dos artigos de opinião e de como o neoliberalismo entra nesta equação enquanto um potencial difusor e amplificador do racismo através da negação de sua existência (ROBERT, 2016).

Ao falarmos de raça podemos elencar suas origens no iluminismo, e de como o homem e sua subjetividade foram tratados pela filosofia enquanto um elemento central e estruturante do mundo (QUIJANO, 2005). Notem que não se trata de qualquer homem, mas sim do homem europeu branco. A partir deste recorte de base de pensamento, se pode classificar o mundo em duas categorias, o homem branco e o restante do mundo, que era simplesmente visto como o "outro". A partir daí, vimos surgir uma grande quantidade de substantivos como nativo, selvagem, índio, negro

\footnotetext{
4 Estendi o recorte até o final de semana após o funeral, pois em jornais de grande circulação os editoriais de sábado e domingo tratam sobre assuntos importantes ocorridos na semana.
} 
que remetem qualificações que salientam um lado animalesco e desprovido de razão, até generalizações que matam, em um sentido figurado, toda uma gama de tradições culturais, sociais e individuais, como é o caso do "índio" e do "negro" (QUIJANO, 2005).

Dito dessa forma, a questão da raça pode trazer uma base científica para a classificar as diferenças. Críticos podem afirmar que diferenças entre povos sempre existiram e que qualificar os outros como bárbaros não é novidade alguma desde o momento em que o império romano cruzou o Rubicão. A questão delineada, de forma inédita na história, é que há uma base científica para essa definição que "justifica" o racismo e é utilizada como bússola, tendo como norte o homem europeu branco (QUIJANO, 2005).

A partir dessa lógica pode se verificar uma discriminação com base na raça no sentido de "um tratamento diferenciado a membros de grupos racialmente identificados" (ALMEIDA, 2016, p. 25). Precisamos entender que por trás das questões de raça há sempre uma questão implícita de poder, que significa, na prática, que um grupo ganha com a discriminação de outro. Por mais básica que a frase acima possa parecer, essa ressalva se faz necessária, pois o caráter sistêmico do racismo está longe de ser um consenso. Nas palavras de Almeida (2018, p. 27):

\footnotetext{
O racismo é definido então pelo seu caráter sistêmico. Não se trata, portanto, de apenas um ato discriminatório ou mesmo de um conjunto de atos, mas de um processo em que condições de subalternidade e privilégio que se distribuem entre grupos raciais se reproduzem nos âmbitos da política econômica e nas relações cotidianas.
}

Em contraposição a esta concepção, está a noção de racismo individualista, que se encaixa muito bem na concepção liberal, que trata a questão como algo pertencente a um indivíduo, em um tipo de ação concreta. A concepção liberal de racismo é facilmente visualizada, pois um comportamento ou atitude racista pode ser filmado e qualquer pessoa tem acesso. Já a concepção estrutural só pode ser entendida em sua completude através de um exercício de reflexão, que está longe de ser simples, como acessar um vídeo em um grupo de WhatsApp. 
A solução na concepção liberal também é de fácil entendimento, basta uma punição individual exemplar para a voltarmos ao normal de uma sociedade que trata todos os indivíduos como iguais, instaurando uma normalidade que até o mais cético dos sujeitos, com um pouco de boa-fé, admitirá ter um caráter sistêmico. Afinal, os porteiros e seguranças, Brasil afora, sabem muito bem quem deve ir pela entrada de serviço $^{5}$ e quem deve ser deixado de fora de algum local, ou mesmo, ser motivo de atenção redobrada 6 .

$\mathrm{Na}$ continuação vamos entender da onde vem essa pretensa igualdade de todos os indivíduos e a influência que as correntes econômicas tiveram nesta tese, que cada dia mais vem sendo propagada como “axioma” pelos liberais.

\section{As diferentes explicações econômicas para o racismo}

Pode-se encontrar os mais variados tipos de explicações do racismo em diferentes correntes econômicas. Antes de entrarmos nas explicações neoliberais, permito-me fazer uma pequena excursão teórica sobre as diferentes concepções que explicam o racismo pelo prisma econômico.

Dando início pelo expecto mais à esquerda do pensamento heterodoxo temos a visão marxista de Oliver Cox (1970) que afirma que o racismo é na verdade um suporte das relações de exploração capitalista. Afinal, segundo o autor, o ódio racial visto nas sociedades modernas não tem paralelo em sociedade não capitalistas. Há então um reforço do modo de produção capitalista neste processo de exclusão que gera por sua vez o racismo.

\footnotetext{
${ }^{5}$ A questão da entrada de serviço é um reflexo de que mesmo os negros e pardos sendo maioria da população, eles ainda são minoria, ou até mesmo inexistem, em condomínios e prédios de luxo. Isso faz com que exista um certo "padrão" em prestadores de serviço. Em uma matéria da jornalista Danielle Valentim (2019), que indaga um porteiro sobre o tema, ele responde: "negro, negro, é prestador de serviço e empregada doméstica. As negras que vejo aqui é tudo doméstica". Esse elitismo da sociedade brasileira fica evidente também em relação aos tipos de profissionais que são instados a recorrer a entrada de serviço, um médico dificilmente teria que percorrer o mesmo caminho que um encanador, mesmo os dois sendo prestadores de serviços.

${ }^{6}$ Uma pesquisa feita pelo Instituto Locomotiva verificou que $7 \mathrm{em}$ cada 10 negros sofreram preconceito em loja, restaurante ou mercado (EXAME, 2021) o que revela um claro desconforto dos negros em relação a essa atenção dedicada exclusivamente pelo viés racial.
} 
É preciso destacar que há uma ampla base de estudos marxistas que contribuem com a noção de Cox (1970) e partem desse referencial teórico como fundamento para debater questões raciais, colocando o combate ao racismo como forma de luta contra o próprio capitalismo. Pode-se destacar as contribuições de Ângela Davis e da ideologia do Partido dos Panteras Negras, assim como autores que analisam o continente africano e formas de resistência por este mesmo prisma - como é o caso de Amílcar Cabral, Patrice Lumunba, Franz Fanon e Kwane Nkrumah. No entanto, se tomarmos a visão marxista como tão bem elucidada por estes autores, veremos que o racismo não se dá somente pelas relações capitalistas. Há ainda um componente mais estruturante que não se extingue junto com o modo de produção.

Passando por uma visão mais liberal com viés keynesiano, temos o autor, Gunnar Myrdal (1944), que vê o racismo como uma sucessão de causas cumulativas que ao fim e ao cabo geram uma desigualdade de condições que impacta em uma diferente inserção do negro na sociedade, sempre em condições mais precárias. Causas estas se referem, por exemplo, a questão de menor acesso à educação, que, por sua vez, gera menos conhecimento sobre outros fatores que são considerados importantes pelo mercado. Como corolário, todas estas causas gerariam um racismo tido como uma decisão racional do mercado. Dessa forma, para acabar com estes elementos causadores de desigualdade se faz necessário um investimento público para pôr fim a estas disparidades e colocar o negro em condição de igualdade (MYRDAL apud ALMEIDA 2018).

Saindo um pouco das visões heterodoxas e liberais, temos a visão neoclássica, corrente da qual o neoliberalismo derivará. Um de seus autores, Garry Becker (1957), afirma que o racismo é orientado por um comportamento que vem de falhas de mercado, ou seja, de um mercado que não gera informações suficientes para que os agentes tomem as decisões corretas. Em resumo, o racismo gerado pelos entes do mercado vem de um comportamento baseado na ignorância. 
Vejam que interessante, o racismo nesta corrente é tratado de maneira individualizada. Os agentes do mercado7, isto é, as empresas, contratam menos negros porque acreditam que estes, devido muitas vezes a baixa taxa de escolaridade, ou a uma percepção de que eles existem para trabalhos mais precarizados, preferem contratar brancos ou mesmo colocar os negros em posições menos rentáveis. Tudo se resume a uma questão de custo-benefício, a empresa contrata alguém que pensa ser mais efetivo e que, ao fim e ao cabo, gerará mais lucro para os empresários.

Na mesma linha, outra corrente, também de matriz neoclássica, posiciona o racismo diretamente como um comportamento individual, a teoria do capital humano (SCHULTZ, 1975; BECKER, 1993; MINCER, 1958). A teoria aborda a questão com base no nível de produtividade. Há diferentes níveis porque os processos históricos de discriminação contra os negros fazem dos brancos detentores de capital humano diferenciado. Isto se reflete nas desigualdades salariais, no sentido de que os brancos por terem uma melhor educação formal tendem a receber melhores salários. Assim sendo, essa tendência será mantida por uma lógica de racionalidade. É irracional começar a pagar um salário maior para uma pessoa por uma simples decisão pessoal, há de se seguir o mercado.

Antes de entrar no ponto central do artigo, que é a análise do neoliberalismo e da questão racial, acredito que se fez necessária essa revisão teórica das doutrinas para ilustrar que, com exceção da concepção Marxista ${ }^{8}$, todas as outras correntes econômicas obliteram o aspecto estrutural do racismo.

\footnotetext{
${ }^{7}$ Ao falarmos sobre agentes do mercado é importante ressaltar que alguns dados empíricos que, mesmo não podendo ser associado a questão do custo benefício em destaque, são importantes para entendermos o mercado de trabalho para a população negra. O livro de 1986 de Clóvis Moura "O negro no mercado de trabalho" já mostrava uma triste realidade e ao compararmos com dados mais recentes, vemos que ainda se mostram atuais. Ao analisarmos a lista de maiores rendimentos salariais os homens brancos estão no topo da pirâmide, a cada $\mathrm{R} \$ 1.000$ recebidos por esse grupo, eram pagos $\mathrm{R} \$$ 758 para mulheres brancas, $\mathrm{R} \$ 561$ para homens pretos ou pardos e $\mathrm{R} \$ 444$ para mulheres pretas ou pardas (GARCIA, 2019). Até mesmo no contexto da pandemia vemos essa disparidade aumentar ainda mais fazendo com que a diferença da taxa de desemprego entre brancos (14\%) e negros (16\%) aumentasse e atingisse seu maior nível desde 2012, quando começou a atual pesquisa do IBGE (CARRAÇA, 2020).

${ }^{8}$ Importante destacar que a teoria marxista traz uma importante contribuição para a questão racial, e permite uma análise mais estruturante. Isto se deve a "algumas características presentes em seu modelo explicativo. A primeira é a visão holística do funcionamento da economia, ou seja, considera que há uma determinação social, e não individual, dos fenômenos econômicos" (CHADAREVIAN,
} 


\section{O neoliberalismo nesta equação}

O fenômeno do neoliberalismo como doutrina hegemônica é muito mais recente que a questão do racismo e de forma alguma pretendemos afirmar aqui a sua interdependência ou qualquer outra coisa do tipo. O tema do qual pretendo tratar se refere ao neoliberalismo como um fenômeno constituinte da própria reificação do racismo nas sociedades, se propondo a tratá-lo como um aspecto individual se nutrindo da máxima liberal que todos são iguais perante, não só à lei, mas ao mérito individual (ROBERT, 2016).

Vimos no apartado anterior outras correntes econômicas que tentam apontar uma justificativa e explicação para o racismo. $\mathrm{O}$ foco aqui é centrar na corrente neoliberal que descende diretamente das ideias da escola de Chicago e da escola Austríaca que, por sua vez, derivam das ideias neoclássicas.

Primeiro cabe fazer uma ressalva a respeito do que é neoliberalismo, já que o termo é mais comumente utilizado por seus críticos e detratores do que pelos próprios partidários destas doutrinas (ENGLAND; WARD, 2016). O termo aqui é empreendido no sentido das reformas econômicas e políticas que foram primeiramente consolidadas pelos governos Pinochet, Reagan e Thatcher, para depois se espraiar para outros países da Europa ocidental até chegarem ao Brasil com as diretrizes do consenso de Washington. Entre as reformas destacamos a não interferência do Estado na economia como uma forma de ampliar a liberdade do indivíduo (BREESER-PEREIRA, 1991) e é nessa questão que vamos enfocar o neoliberalismo como apoio para a consolidação do racismo estrutural.

O neoliberalismo pode ser analisado de duas maneiras ${ }^{9}$, a primeira com um prisma economicista que tem como foco instituições e políticas relacionados à relação

2007, p.75). Enquanto em outras concepções liberais o indivíduo precede a sociedade, na teoria marxista a sociedade precede o indivíduo.

9 É prudente ressaltar que o debate a respeito do neoliberalismo se põe muito mais amplo que nas duas vertentes exemplificadas neste trabalho. Saliento estas duas pois são as mais relevantes para o debate proposto. Para mais informações o professor Daniel Pereira Andrade (2019) faz um debate interessante sobre as vertentes e o uso do termo no artigo "O que é o neoliberalismo? A renovação do debate nas ciências sociais". 
de causa e efeito a partir de diretrizes econômicas. Essa corrente de análise está muito bem representada por David Harvey em muitos dos seus livros (1992; 2005; 2014). A segunda, que será utilizada neste artigo, é a visão foucaultiana que foi sintetizada por Pierre Dardot e Christian Laval (2016) em seu livro Nova razão do mundo e por Wendy Brown (2019), em Nas ruínas do neoliberalismo: a ascensão da política antidemocrática no ocidente.

Nesta abordagem, o foco está muito mais em princípios que orientam e relacionam o Estado, os sujeitos e a subjetividade, e revelam como essa ideologia molda as subjetividades desta "nova razão" neoliberal que tem o poder de fazer com que os indivíduos, mais do que nunca, pensem a si próprios como um reflexo do mercado - ou seja, pensem a si próprios como uma empresa (DARDOT; LAVAL, 2016; BROWN, 2019).

Os indivíduos, segundo a doutrina, são a principal engrenagem de qualquer sociedade, por sua capacidade inata de se desenvolver e empreender. Segundo a lógica, que emplaca juntamente a noção de empreendedorismo, destaca-se que hoje, em um mundo globalizado, não há mais lugar para pessoas que querem depender de um emprego vitalício, ajuda do Estado ou qualquer outra subvenção a nível individual ${ }^{10}$. Dessa forma, pensando a si próprio como uma empresa, o próprio indivíduo se torna o fator chave do seu sucesso e, por uma lógica binária, de seu próprio fracasso - eximindo o Estado de qualquer forma de culpa ou compromisso.

A falta de qualquer menção da questão racial até aqui é proposital, pois toda a noção neoliberal de liberdade individual, iniciativa e empreendedorismo, oblitera qualquer menção a raça (ROBERT, 2016). No sentido de que somos todos dotados das mesmas oportunidades ${ }^{11}$ nesta nova sociedade, que alguns até definem como pós-

\footnotetext{
${ }^{10}$ Cabe mencionar aqui que a doutrina neoliberal, desde seus mais famosos intelectuais, com o é o caso de Milton Friedman, que inclusive utilizava o termo "neoliberal" para enfatizar a originalidade de suas ideias (FRIEDMAN, 1951), pressupõe a ideia de uma renda mínima, só que esta é mais focalizada para os mais pobres entre os pobres e isso de forma alguma suplanta a ideia de um individualismo empreendedor.

${ }^{11}$ Aqui há de se ressaltar que essa questão de igualdade de oportunidade não supões de forma alguma a igualdade entre os indivíduos tal como supõe o pensamento iluminista. No neoliberalismo há autores, como é o caso de Hayek (HARVEY, 2014), que tratam a desigualdade de uma sociedade como um valor positivo e imprescindível da humanidade, colocando como algo que pode motivar indivíduos a se desenvolverem.
} 
racial. Colocando de uma forma mais coloquial: "não importa a cor da sua pele para crescer no capitalismo".

Dito isso, esse discurso é apropriado como uma forma de dizer, ao mesmo tempo, que o racismo como prática estruturada não existe e a melhor solução para esse problema é dar condições, leia-se liberdades, para que os negros ou outras minorias, possam competir nessas sociedades com possibilidades ilimitadas. Cabe a cada um buscar seu lugar ao sol através de seu próprio esforço.

Feita toda essa análise teórica, posso agora destacar que ao eliminar as questões raciais de uma sociedade que se fundamenta, justamente, no quesito raça como pedra angular de suas relações (QUIJANO, 1992; ALMEIDA, 2018), ela acaba por reiterar o racismo de sua pior forma possível, atribuindo toda a culpa de seus fracassos às próprias pessoas vitimizadas. Assim sendo, caminhos se abrem para afirmações de cunho racista dizendo que há poucos negros nas universidades porque estes não se esforçam o suficiente. Esta crítica está colocada com muita ênfase nas formulações contrárias às políticas de ações afirmativas, principalmente às cotas para negros em universidades públicas. Há, também, se apoiando na noção de democracia racial, aqueles que afirma que negros e brancos teriam a mesma “capacidade” para exercerem suas potências, desconsiderando as desigualdades sociais e de condições estabelecida entre eles. Alguns até afirmam que há uma certa atribuição diferente para cada tipo de pessoa, coroando assim as frases odiosas ditas pelo senso comum.

De maneira sintética, cabe entender a doutrina neoliberal com uma face desta sociedade racista que, através de sua concepção meritocrática, reforça a estrutura racial desigual, enquanto modifica os processos de racialização como uma forma de criar uma certa "neutralidade" e garantir que o componente racial não seja um empecilho para o sucesso. Assim, há uma espécie de verniz que blinda o racismo de seu caráter excludente através de um projeto moral com práticas ancoradas na meritocracia.

Analisando mais especificamente o caso brasileiro, o verniz que reforça esta estrutura racial desigual pode ser creditado a um pensamento hegemônico baseado na 
democracia racial ${ }^{12}$ que, mesmo depois de toda uma gama de escritos desmistificando as teses de Gilberto Freyre (SOUZA, 2015; HASELBALG, 2005), ainda é usado como base para assimilar e oprimir minorias a partir de um amalgama unificado de raças em torno da supremacia branca - o que significa um verdadeiro etnocídio (QUIJANO, 2005). Roger Bastide e Florestan Fernandes em sua obra Brancos e Negros em São Paulo (1974) já deixavam claro que o país, mesmo sobre o manto da "democracia racial", estava repleto de práticas discriminatórias.

Ao chegar neste ponto a pergunta que se pode fazer é: Qual a novidade? Já que outros tipos de doutrinas econômicas também tinham sua maneira de se portar como isonômicas no tratamento das pessoas. $\mathrm{O}$ neoliberalismo, neste caso, reforça e transforma a questão racial de uma estrutura que edifica as relações sociais, econômicas e políticas enquanto um problema individualizado e, portanto, impossível de ser solucionado ou até mesmo visualizado dessa forma (ROBERT, 2016).

Tratando o racismo como uma manifestação individual, mesmo com políticas que tenham foco em distribuição de renda, não se reverterá o problema, pois jamais alterará as estruturas que permitem hoje que o racismo se manifeste.

\section{Os editoriais de opinião sobre o caso George Floyd}

A minha ideia foi tentar identificar nos artigos de opinião sobre o caso George Floyd (pela notoriedade e importância que teve, tanto na mídia brasileira quanto a nível mundial), a existência de alguma citação que coloque o episódio como uma ação individual de um policial e se há menções sobre o racismo estrutural (ALMEIDA, 2018).

Para minha gratificante surpresa, não encontrei nenhuma citação entre os artigos pesquisados que trata a ação, que resultou na morte de George Floyd, como uma ação individual de um policial, que era uma das hipóteses iniciais. Tomei como base a ideologia neoliberal que está presente nas sociedades e cogitei que isso seria evidenciado, pelo menos em algum artigo.

\footnotetext{
${ }^{12}$ A tese de Gilberto Freyre forneceu as bases para uma nova interpretação do Brasil, dando um valor positivo a mestiçagem e afirmando que o preconceito de raça não existe no país.
} 
Os autores, por sua vez, são enfáticos em denunciar, de diferentes maneiras, o caso como rotineiro nas polícias, tanto no Brasil quanto nos Estados Unidos. A realidade Brasileira, para qualquer observador com boa vontade, permite essa visualização, já que alguns dias antes da morte de George Floyd, um menino de 14 anos chamado João Pedro Matos Pinto morreu dentro de sua casa que foi alvejada por mais de setenta tiros ${ }^{13}$ efetuados por policiais em uma ação no complexo do Salgueiro em São Gonçalo, Rio de Janeiro.

Agora ao analisar minha segunda hipótese que inquire se o racismo estrutural é levado em consideração nas análises, vemos que são poucos os que jogam luz para o problema do racismo pelo prisma estrutural. Antes de passarmos para as análises pormenorizadas, cabe aqui uma elucidação, mesmo sendo considerado que as práticas policiais são motivadas por questões raciais e preconceituosas, essa visão não se encaixa na concepção de racismo estrutural de Silvio Almeida, pois ela é muito mais ampla e abrange uma vasta gama de privilégios que vai além da abordagem policial.

\section{Como o caso foi tratado nos editoriais}

O Caso George Floyd reverberou de uma maneira nunca vista, pelo menos em um passado recente, questões relacionadas ao racismo na mídia Brasileira. Nos artigos pesquisados, considero a postura da ombudsman da Folha de São Paulo, Flavia Lima, como uma das mais coerentes com a situação ensejada: "em uma semana, a morte de George Floyd, assassinado por um policial nos EUA, fez muito mais pelo debate na imprensa Brasileira acerca do racismo do que ela mesma se dispôs a fazer em décadas” (LIMA, 2020).

A jornalista salienta ainda que o episódio revelou um despreparo para lidar com a pauta, por um motivo deveras simples, pela falta de representatividade racial dos meios de comunicação. A própria Folha de São Paulo tem apenas dez negros entre mais de duzentos colunistas. Tal conjuntura demonstrou que "pela primeira vez

\footnotetext{
13 “A casa onde o menino João Pedro Matos Pinto brincava com os primos, antes de ser morto durante uma operação policial na tarde de segunda (18/05/2020), tem hoje cerca de 70 marcas de tiros, contaram as pessoas que foram ao local nesta terça (19/05/2020)" (BARBON, 2020).
} 
jornalistas brancos ficam sem saber o que fazer com o monopólio de opinião e de imagem que sempre detiveram" (LIMA, 2020).

Esta falta de representatividade, por si só, deveria elevar o debate a respeito do racismo estrutural e não como questão a ser colocada em pauta quando há uma comoção geral, geralmente envolvendo eventos violentos com crianças ou mulheres e, não raro, internacionais por parte das forças de segurança pública.

Ainda mais em um país como o Brasil, com um número de homicídios anuais maiores do que os de países em guerra, e em sua grande maioria vitimam jovens negros e moradores de periferias. Para se ter uma ideia, apenas em 2018, pretos e pardos representaram 75,7\% das vítimas de homicídios, com uma taxa de homicídios por 100 mil habitantes de 37,8. Só para nível de comparação, entre não-brancos a taxa foi de 13,9 o que significa que, em 2018, para cada não negro assassinado 2,7 negros foram mortos (ATLAS DA VIOLÊNCIA, 2020).

Salvo algumas execráveis exceções ${ }^{14}$, os episódios violentos são sempre retratados com pesar e profunda indignação por grande parte dos jornalistas. No entanto, o objetivo aqui é muito maior do que apenas verificar o pesar, justo e merecido, de parte da mídia por qualquer morte. Quero entender se há um tratamento do racismo como estrutura social.

Por isso resolvi fazer uma imersão no universo jornalístico para entender como foi retratada a morte de George Floyd e todos os aspectos associados a realidade brasileira que foram feitos pelos mais diferentes articulistas. O objetivo foi analisar as opiniões e verificar o modo como elas qualificaram o episódio. Como recorte proposto, foram selecionados os artigos de opinião, desde o dia do assassinato, até o dia do sepultamento em Houston-Texas. O veículo de análise escolhido foi a Folha de São Paulo, por ser um jornal de grande circulação nacional e com uma postura mais liberal ${ }^{15}$ do que seus concorrentes diretos, como é o caso do jornal Estado de São Paulo

\footnotetext{
${ }^{14}$ Alguns jornalistas defenderam a ação da polícia, justificando que se tratava de ex-presidiário e estava sob o efeito de drogas, no entanto, foram tão poucas menções que não cabe citar nomes neste artigo para não publicitar atitudes racistas e lamentáveis.

15 O próprio jornal tem posições que encaram o aborto como questão de saúde pública, é contra as medidas punitivistas e carcerárias, liberalização e descriminalização do consumo de drogas (FOLHA DE SÃO PAULO, 2018). Mesmo tendo uma posição firme contra práticas racistas e que as mesmas
} 
e o Globo. A escolha foi motivada a partir da premissa de que, em um jornal liberal, seria mais fácil encontrar menções relacionadas a questão estrutural.

Esta pesquisa não se fecha com este artigo, ficando aberta para novos projetos, que poderiam focar no modo como esta questão é tratada em jornais mais "conservadores".

Para escolher os artigos utilizei o próprio buscador do site Folha fazendo o recorte por datas proposto acima e filtrando a busca apenas por artigos de opinião, pois seria neles em que possivelmente encontraria relatos sobre o racismo estrutural. Em reportagens tradicionais os dados refletem por vezes os fatos, se eximindo de opiniões contundentes.

Feitas as orientações de busca, foram encontrados trinta e quatro artigos a partir das palavras "George Floyd". A partir daí, foi empreendida uma análise minuciosa de todos os resultados que havia menção ao nome. Não é objetivo desta pesquisa fazer uma análise quantitativa, no sentido de buscar porcentagens de citações ou mesmo fazer um cálculo amostral. O Importante é entender como está sendo debatida a questão do racismo, se ele é visto como um aspecto individual e principalmente se há menções estruturantes.

Imediatamente já foi possível retirar alguns resultados da análise, pois como a busca foi nominal, alguns artigos faziam menção ao nome, mas falavam de outros temas, como por exemplo no Painel S.A que fala sobre empresas de Wall Street apoiando o protesto (OLIVEIRA; GRAZINI, 2020), Zuckerberg como amigo dos poderosos (GUIMARÃES, 2020) e até mesmo artigos falando somente da situação de Trump comparada com a brasileira (MOTA, 2020). Isso aconteceu com oito artigos. As citações que efetivamente trouxeram à baila as temáticas relacionadas ao racismo merecem um destaque pormenorizado.

Começo essa análise pelo próprio editorial da Folha do 31/05/2020. Os editoriais dominicais são os mais relevantes, pois têm maior tiragem e número de visualizações, além de normalmente tratarem de assuntos importantes ocorridos na semana.

devem ser punidas com o "devido rigor judicial" (FOLHA DE SÃO PAULO, 2021) o jornal não se posiciona a favor de cotas raciais e sim cotas "baseadas em critérios objetivos, como renda ou escola de origem" (FOLHA DE SÃO PAULO, 2018). 
Neste editorial, que sintetiza bem a posição do jornal, faz-se questão de denunciar de formal cabal a "covardia monstruosa do policial e a desproporção de força por ele utilizada”. Também é feita uma importante ressalva sobre como um país que é opulento em sua economia, se mostra cada vez mais desigual. Um dos argumentos mais fortes do editorial, importante para nossa análise, é que há toda uma institucionalização da violência policial, inclusive com bases legais, nos Estados Unidos através da doutrina da imunidade qualificada - enquanto no Brasil houve uma tentativa de se caminhar nesse sentido com a implementação do pacote anticrime que tinha entre suas atribuições ampliações do excludente de ilicitude (FOLHA DE SÃO PAULO, 2020).

Em grande parte dos artigos analisados há esta ênfase importante na questão da banalização da violência, racismo, abuso por parte de forças policiais. Contudo quando falamos sobre o tema a partir do prisma do conceito de racismo estrutural desenvolvimento por Silvio Almeida (2018), vemos que são poucos os artigos que tratam do tema em sua amplitude. No sentido de que todas as questões institucionais e relativas à banalização da violência contra negros estão intrinsecamente ligadas a faceta estruturante do racismo e não é entendendo apenas a relação policial que se pode ter uma abrangência do todo.

Essa menção foi encontrada mais em artigos de pessoas ligadas aos movimentos negros, com notáveis e importantes exceções como é o caso dos articulistas Demétrio Magnoli ${ }^{16}$ e Alexandre Schneider.

\section{O racismo estrutural em perspectiva}

Nos dezoito artigos analisados, menções ao racismo estrutural aparecem em quatro deles, sendo um do Jornalista e escritor Sergio Rodrigues (2020) e outro da Djamila Taís Ribeiro (2020), muito conhecida por sua ligação com movimentos

\footnotetext{
${ }^{16}$ É preciso destacar que mesmo tendo uma postura positiva em relação ao caráter estrutural do racismo, o autor tem uma longa trajetória crítica sobre as cotas raciais e reforça o discurso liberal (MAGNOLI, 2013; MAGNOLI, 2009).
} 
feministas negros - levando em conta, ainda os textos de Magnoli (2020) e Schneider (2020) citados acima.

Daremos início a análise, pelo artigo do Sergio Rodrigues (2020), pois ele é o único que cita o termo "racismo estrutural" literalmente e é enfático em afirmar que "é impossível entender o mundo" sem esta terminologia. Segundo o jornalista e escritor, a expressão, que tem menos de um século, é algo que "se confunde com a paisagem, representações culturais, códigos não escritos, modos de entender e ver o mundo" e se torna quase que imperceptível. Uma importante contribuição do artigo, que será discutida mais adiante, e foi amplamente debatida pelos meios de comunicação está no fato de discorrer sobre o porquê que no Brasil não há um verdadeiro "escândalo nacional" sobre as diversas mortes de negros causadas pela polícia.

$\mathrm{O}$ artigo da Djamila (2020) igualmente traz à tona a questão do racismo como um elemento muito mais amplo do que os demais artigos apresentam. No entanto, sua ênfase está na questão de que a branquitude brasileira deve "se mobilizar contra o sistema que a beneficia" e ainda "é tão racista que só com a morte de um americano negro foi capaz de mobilizar o debate racial”. Ela finaliza o artigo com uma mensagem de otimismo em relação a onda de protestos, o qualificando como um "levante em curso" e quem se opor será atropelado pela "marcha da história".

Finalizando a análise do racismo estrutural em editoriais de opinião, fecho com as análises dos artigos de Magnoli (2020) e Schneider (2020). Os dois, mesmo sem mencionar o termo, conseguem abordar de maneira direta a questão do racismo para muito além do homicídio policial com requintes de crueldade. Schneider salienta que “do ponto de vista simbólico, esquadrinhamos inconscientemente os 'lugares' de brancos e negros" pelo fato de que aprendemos a ser racistas desde cedo, por não enxergamos negros em espaços de poder. Isso é um aspecto estrutural, no sentido de que a sociedade seja orientada e facilitada para o acesso de uma determinada classe, que se beneficia dessa estrutura. $O$ poder simbólico dessa perpetuação contribui para que as mortes de negros nas periferias do Brasil não causem a mesma comoção que outras mortes. Este poder simbólico é apenas um dos fatores da equação e existem outras questões que também impactam nessa falta de comoção, como vários autores 
ressalvam que isso seja uma herança do nosso longo passado escravocrata (JESSÉ, 2017).

Demétrio Magnoli (2020) segue a mesma linha, em seu artigo ele explica que mesmo que o racismo tenha saído dos códigos legais ele não saiu das consciências americanas. Ainda que ele esteja se referindo aos Estados Unidos, nós podemos traçar paralelos com a questão nacional, mesmo o Brasil não tendo um histórico de leis segregacionistas. Esse aspecto ligado às consciências das pessoas é um reflexo do poder estruturante do racismo que não pode ser apagado com indignações inflamadas ou mesmo ações pontuais relacionadas a violência.

Fazendo um adendo a respeito das leis segregacionistas, há entre os artigos analisados um que aborda o aspecto legal das ações policiais (AMPARO, 2020). Este artigo, e por isso que eu o menciono para finalizar a análise, faz referência ao fato de que as ações policiais não são um desvio de conduta, como a tradição neoliberal nos insta a entender, mas são a "reencarnação da própria função de controle social para as quais as polícias foram originalmente criadas”. Ao elencarmos um marco legal aqui no Brasil, segundo o autor, podemos pensar que no período pós-abolição, quando temos que "o documento fundante de nossa república não foi uma carta de direitos, mas sim o código penal de 1890 para controlar a população recém liberta” (AMPARO, 2020).

Finalizo destacando a dificuldade de apresentar o debate sobre o racismo estrutural, pois admitir a sua existência implica em aceitar o aspecto segregacionista de uma sociedade que beneficia os brancos, não simplesmente excluindo um grande contingente de negros e negras, mas se beneficiando desta exclusão ao se manter na posição de liderança nesta sociedade.

\section{Considerações finais}

Não pretendo dar a palavra final sobre a questão racial e seus desenlaces. $\mathrm{O}$ meu ponto aqui é, utilizando das palavras do Professor Kabengele Munanga (1999), entender que o racismo nesta sociedade neoliberal só pode ser vencido em uma via de mão dupla que compreende fatalmente a entrada de mais negros em posições de 
mando e de poder e ao mesmo tempo uma identificação do negro com a sua própria cultura.

Há de se deixar claro que há uma hegemonia branca que vem desde os tempos do iluminismo, isso é muito bem ilustrado por Aníbal Quijano (2005) em seu texto clássico. Conforme mencionado acima, o Brasil, com o mito da democracia racial, pôde fazer com que essa hegemonia branca se escamoteasse em uma pretensa igualdade.

O que isto significou na prática? Que para se ter uma inserção social era preciso se aproximar da condição de branco, seja culturalmente ou em seus espaços de poder e ao mesmo tempo, em uma equação de soma zero mata a sua própria identidade negra (ANDRE, 2008). Vemos muitos exemplos da questão particular brasileira da "ideologia do branqueamento" ${ }^{17}$ em que se tenta descolar da imagem de negro partindo de um gradiente de cores que soam como um eufemismo abstrato, podendo ser utilizado para ser "aceito" em diferentes espaços. Essa questão, juntamente com o mito da democracia racial, é um importante componente do racismo Brasileiro.

Então há pessoas que buscam ascender pelas métricas brancas de educação, sucesso nos negócios e ao conseguirem chegar nestes locais se esquecem da sua condição de negro ou a abandonam literalmente, como em frases ditas por negros que simplesmente esquecem da sua cor. Tamanha era a carga hegemônica da concepção de democracia racial no Brasil que o próprio movimento negro, antes da década de 1970, tratava o racismo como uma questão ética e de ignorância (GUIMARÃES, 2003), no sentido de que se os negros conseguissem uma melhor educação poderiam sair de sua condição de pobreza.

No entanto, mesmo com a ascensão pela educação, o estigma relacionado com a cor da pele não os deixaria de maneira tão simples. Por isso, nos anos 1970 houve, pelo próprio movimento negro, uma nova ressignificação da forma como a negritude era vista e valorizada (GUIMARÃES, 2003). Com o objetivo de colocar o negro como

\footnotetext{
${ }_{17}$ 'No século XIX e meados do século XX, a elite brasileira estruturou a 'ideologia do branqueamento' baseada na premissa de que era necessário embranquecer o país (tornar a população branca mesmo), uma vez que ser negro era considerado ruim" (DALTRO, 2019, online).
} 
contraponto ao discurso aglutinador da democracia racial. Era preciso ter orgulho do ser negro, do ser preto, de suas origens e de suas raízes.

Toda essa restruturação significou que, além de educação, que é uma petição deveras importante, há também a questão de se valorizar como tal e tentar, mesmo que de uma forma precária, mover a estrutura da balança que pende a raça branca em uma posição tão desigual na estrutura da sociedade.

Pensando a sociedade neoliberal, é preciso combater a unicidade dessa pretensa sociedade "pós-classe”, "pós-racismo”, mesmo que seja no campo das ideias. Há de denunciar as desigualdades, sejam elas sociais e raciais, mas é preciso ainda, mesmo que seja em um horizonte de médio e longo prazo, uma retomada do processo de ressignificação do ser negro como um elemento de igualdade de importância com a branquitude dominante.

Pode parecer um pouco utópico, mas a questão de um horizonte, mesmo que seja fantasioso, é sempre um primeiro passo em busca de uma nova concepção de mundo. Afinal, se não conseguimos imaginar uma situação diferente, é melhor que sentemos e esperemos pela terra arrasada, que fatalmente virá.

\section{Referências}

ANDRADE, Daniel Pereira. O que é o neoliberalismo? A renovação do debate nas ciências sociais. Revista Sociedade e Estado - Volume 34, Número 1, p.211-239, janeiro/Abril 2019.

ANDRÉ, Maria da Consolação. O ser negro: a construção da subjetividade em afrobrasileiros. Brasília: LGE, 2008.

AMPARO, Thiago. Negros queimam mito da democracia americana. Folha de São Paulo. Opinião. São Paulo. Grupo Folha. [31/05/2020]. Disponível em: https://www1.folha.uol.com.br/colunas/thiago-amparo/2020/o5/negros-queimammito-da-democracia-americana.shtml. Acesso em: 17 nov 2020.

ALMEIDA, Silvio Luiz de. O que é racismo estrutural. Belo Horizonte (MG): Letramento, 2018.

BARBON, Júlia. Casa onde menino de 14 anos foi morto tem cerca de 70 marcas de tiro. Folha de São Paulo. Cotidiano. São Paulo. Grupo Folha. [20/05/2020]. Disponível em: 
https://www1.folha.uol.com.br/cotidiano/2020/o5/casa-onde-menino-de-14-anos-foimorto-tem-cerca-de-70-marcas-de-tiro.shtml. Acesso em: o7 jun 2021.

BASTIDE, R.; FERNANDES, F. Brancos e negros em São Paulo. São Paulo. Companhia Editora Nacional. Brasiliana n.9 305. 3a edição. 305 pp. 1974.

BECKER, Garry. Human capital: a theoretical and empirical analysis, with special reference to education. Chicago: The University of Chicago Press, 1993.

BECKER, Gary. Economics of discrimination. Chicago: University of Chicago press. 1957.

BRESSER-PEREIRA, Luiz Carlos. A Crise da América Latina: consenso de Washington ou Crise Fiscal? Pesquisa e Planejamento Econômico, Rio de Janeiro, v. 21, n. 1, p. 323, abril 1991.

BROWN, Wendy. Nas ruínas do neoliberalismo: a ascensão da política antidemocrática no ocidente. São Paulo: Editora Filosófica Politeia, 2019.

CARRAÇA. Thais. Taxa de desemprego chega a $17 \%$ entre mulheres e $16 \%$ entre negros. Folha de São Paulo. Mercado. São Paulo. Grupo Folha. [23/10/2020]. Disponível em: https://www1.folha.uol.com.br/mercado/2020/10/taxa-de-desemprego-chega-a-17entre-mulheres-e-16-entre-negros.shtml. Acesso em: o7 jun 2021.

CHADAREVIAN, Pedro Caldas. Os precursores da interpretação marxista do problema racial. Crítica marxista. São Paulo, v. 1, n.24, p. 73-92. 2007.

COX, Oliver. Caste, class and race: a study of social dynamics. Nova York: Londres; Modern reader paperbacks, 1970.

DALTRO, Luana Mendes. A Ideologia do branqueamento: tudo que você precisa saber. Portal GELEDÉS. Artigos e Reflexões [24/o9/2019]. Disponível em: https://www.geledes.org.br/a-ideologia-do-branqueamento-tudo-que-voce-precisasaber/. Acesso em: $25 \mathrm{fev} 2021$.

DARDOT, Pierre; LAVAL, Christian. A nova razão do mundo: ensaio sobre a sociedade neoliberal. São Paulo: Boitempo, 2016.

ENGLAND, Kim; WARD, Kevin. Theorizing neoliberalization. In: SPRINGER; BIRCH; MACLEAVY (org.). The handbook of neoliberalism. New York: Routledge, 2016. p. $50-60.20$

EXAME. 7 em cada 10 negros sofreram preconceito em loja, restaurante ou mercado. Revista Exame: Bússola. São Paulo: Grupo Abril, [30/04/2021]. Quinzenal. Disponível em: https://exame.com/bussola/7-em-cada-10-negros-sofreram-preconceito-em-lojarestaurante-ou-mercado/. Acesso em: 17 nov 2020 
FOLHA DE SÃO PAULO. O que a Folha pensa. Poder. São Paulo: Grupo Folha, [18/o2/2018]. Diário. Disponível em: https://www1.folha.uol.com.br/poder/2018/o2/oque-a-folha-pensa.shtml. Acesso em: 07 jul 2020.

FOLHA DE SÃO PAULO. Sem justiça, sem paz. São Paulo: Grupo Folha, [31/o5/202o]. Diário. Disponível em: https://www1.folha.uol.com.br/opiniao/2020/o5/sem-justicasem-paz.shtml. Acesso em: 17 nov 2020.

FOLHA DE SÃO PAULO. Injúria racial e racismo. São Paulo: Grupo Folha, [27/03/2021]. Diário. Disponível em: https://www1.folha.uol.com.br/opiniao/2020/o5/sem-justica-sem-paz.shtml. Acesso em: 17 nov 2020.

FRIEDMAN, Milton. "Neoliberalism and its prospects”. Farmand,17 February, pp. 89-93. 1951.

GARCIA, Diego. Desemprego aumenta só entre os negros no $3^{\circ}$ trimestre, aponta IBGE. Folha de São Paulo. Mercado. São Paulo: Grupo Folha, [20/11/2019]. Disponível em: https://www1.folha.uol.com.br/mercado/2019/11/desemprego-aumenta-so-entre-osnegros-no-3o-trimestre-aponta-ibge.shtml. Acesso em 17 jun 2021.

GUIMARÃES, Antônio Sérgio Alfredo. Como trabalhar com "raça" em sociologia. Educação e Pesquisa. São Paulo, v.29, n.1, p. 93-107, jan./jun. 2003.

GUIMARÃES, Lucia. Zuckerberg se tornou o amigo dos autocratas. Folha de São Paulo. Eleição nos Estados Unidos. São Paulo: Grupo Folha, [03/06/2020]. Disponível em: https://www1.folha.uol.com.br/colunas/lucia-guimaraes/2020/o6/zuckerberg-setornou-o-amigo-dos-autocratas.shtml. Acesso em: 17 nov 2020.

HASENBALG, Carlos. Discriminação e desigualdades sociais no Brasil. Belo Horizonte: editora UFMG, RJ, 2005.

HARVEY, David. A condição pós-moderna. 17. Ed. São Paulo: Loyola, 1992.

HARVEY, David. O novo imperialismo. São Paulo: Loyola, 2005.

HARVEY, David. O Neoliberalismo: história e implicações. 5. ed. São Paulo: Edições Loyola, 2014.

INSTITUTO DE PESQUISA ECONÔMICA APLICADA (IPEA); DIRETORIA DE ESTUDOS E POLÍTICAS DO ESTADO, DAS INSTITUIÇÕES E DA DEMOCRACIA (DIEST); FÓRUM BRASILEIRO DE SEGURANÇA PÚBLICA (FBSB). Atlas da violência 2020 (Principais resultados), 2020. 
LIMA, Flavia. Sim, somos racistas. Folha de São Paulo. Opinião. São Paulo: Grupo Folha, [07/o7/2020]. Disponível em: https://www1.folha.uol.com.br/colunas/flavialima-ombudsman/2020/o6/sim-somos-racistas.shtml. Acesso em: 16 nov 2020.

MAGNOLI, Demétrio. Uma gota de sangue: história do pensamento racial. São Paulo: Contexto. 2009.

MAGNOLI, Demétrio. Brasil e a "nação diaspórica". O Globo. Opinião. Rio de Janeiro: Grupo Globo. [07/11/2013]. Diário. Disponível em: https://oglobo.globo.com/opiniao/o-brasil-a-nacao-diasporica-10704825. Acesso em: 25 fev 2021.

MAGNOLI, Demétrio. Nos EUA, o racismo saiu dos códigos legais, mas não das consciências. Folha de São Paulo. Opinião. São Paulo: Grupo Folha, [05/07/2020]. Disponível: https://www1.folha.uol.com.br/colunas/demetriomagnoli/2020/o6/noseua-o-racismo-saiu-dos-codigos-legais-mas-nao-das-consciencias.shtml. Acesso em: 17 nov 2020.

MATTOS, Hebe. Mudança de ventos. Folha de São Paulo. Opinião. São Paulo: Grupo Folha, [09/11/2020]. Disponível em: https://www1.folha.uol.com.br/opiniao/2020/11/mudanca-de-ventos.shtml. Acesso em: 16 nov 2020.

MINCER, J. Investment in Human Capital and Personal Income Distribution. Journal of Political Economy, 1958.

MOTA, Vinicius. O povo contra o populismo. Folha de São Paulo. Opinião. São Paulo: Grupo Folha, [07/07/2020]. Disponível em: https://www1.folha.uol.com.br/colunas/viniciusmota/2020/o6/o-povo-contra-opopulismo.shtml. Acesso em: 16 nov 2020.

MOURA, Clóvis. PESTANA, Mauricio. O negro no mercado de trabalho. Conselho de Participação e Desenvolvimento da Comunidade Negra. São Paulo. 1986.

MYRDAL, Gunnar. An American dilemma: the negro problem and the American democracy. Nova York; Londres: Harpers \& Brothers, 1944.

MUNANGA, Kabengele. Rediscutindo a mestiçagem no Brasil: identidade nacional versus identidade negra. Petrópolis, RJ: Vozes, 1999.

NOGUEIRA, Oracy. Preconceito racial de marca e preconceito racial de origem, sugestão de um quadro de referência para a interpretação do material sobre relações raciais no Brasil. Tempo Social, revista de sociologia da USP, v. 19, n. 1, 2006.

OLIVEIRA, Felipe. GRAZINI, Mariana. Wall Street apoia protesto, mas EUA ainda debatem racismo no acesso a crédito. Folha de São Paulo. Painel S.A. São Paulo; Grupo 
Folha,

[02/o7/2020].

Disponível

em:

https://www1.folha.uol.com.br/colunas/painelsa/2020/o6/wall-street-apoia-protestomas-eua-ainda-debatem-racismo-no-acesso-a-credito.shtml. Acesso em: 17 nov 2020.

QUIJANO, Aníbal. Colonialidade do poder, Eurocentrismo e América Latina. In: Colonialismo; Modernidad; Capitalismo; Poder Político; Sociedad; Historia; Eurocentrismo; America Latina. CLACSO, Consejo Latinoamericano de Ciencias Sociales. Buenos Aires, 2005.

RIBEIRO, Djamila. O enfrentamento ao racismo precisa ser mais do que posts para aliviar a consciência. Folha de São Paulo. Opinião. São Paulo: Grupo Folha, [04/o7/2020]. Disponível em: https://www1.folha.uol.com.br/colunas/djamilaribeiro/2020/o6/o-enfrentamento-ao-racismo-precisa-ser-mais-do-que-posts-paraaliviar-a-consciencia.shtml. Acesso em: 17 nov 2020.

ROBERT, David. Neoliberalism and race. In the handbook of neoliberalism. New York: Routledge, 2016. p. 209-2016.

RODRIGUES, Sérgio. George Floyd. Folha de São Paulo. Opinião. São Paulo: Grupo Folha, [03/o6/2020]. Disponível em: https://www1.folha.uol.com.br/colunas/sergiorodrigues/2020/o6/george-floyd.shtml. Acesso em: 17 nov 2020.

SCHEIDER, Alexandre. Racismo se 'desaprende' na escola. Folha de São Paulo. Opinião. São Paulo: Grupo Folha, [04/06/2020]. Disponível em: https://www1.folha.uol.com.br/colunas/alexandre-schneider/2020/o6/racismo-sedesaprende-na-escola.shtml. Acesso em: 17 nov 2020.

SCHUlTZ, T. W. O Capital Humano: investimentos em educação e pesquisa. Tradução de Marco Aurélio de Moura Matos. Rio de Janeiro: Zahar, 1973.

SOUZA, JESSÉ. A tolice da inteligência brasileira: ou como o país se deixa manipular pela elite, São Paulo: Leya, 2015.

SOUZA, JESSÉ. A elite do atraso: da escravidão à lava jato. Rio de Janeiro: Leya, 2017.

VALENTIM, Danielle. O ano é 2019 e os negros ao seu redor estão te servindo ou se divertindo? Campo Grande News. Comportamento. Campo Grande: Campo Grande News, [20/11/2019]. Disponível em: https://www.campograndenews.com.br/ladob/comportamento-23-08-2011-o8/o-ano-e-2019-e-os-negros-ao-seu-redor-estao-teservindo-ou-se-divertindo. Acesso em: o7 de Jul 2021. 